\title{
WHY LABORATORY ANIMALS DIE
}

$\mathrm{D}$ URING April 11-13 there were two meetings at the Royal Veterinary College, London. On the first two days the Laboratory Animals Bureau held its ninth annual congress of animal technicians; and on the third day a symposium on infections in laboratory animals attempted to summarize current problems in this field.

The symposium was the fourth to be held, and its main audience consisted of graduates, in contrast to the congress. The fact that such meetings continue to attract attention each year is of interest in itself, indicating that the animal house is no longer considered unworthy of scientific consideration, although in many cases it still attracts too small a proportion of the laboratory budget.

To compare laboratory animals with chemical reagents is an analogy that has become hackneyed and, if followed too far, is misleading. Reagents they may be to the biologist, but they have characteristics distinguishing them sharply from the inanimate substances with which the chemist has to deal. They are not inanimate but living; and they are not a homogeneous mass but distinct individuals, however nearly the ideal of individual similarity or uniformity may be approached.

Laboratory animals are thus exposed to one especial hazard, namely, accidental intercurrent infection. As a result of this hazard the animal may die, or the group lose any degree of uniformity it may have possessed before infection or might be expected to possess without it, and then its value as a reagent is diminished or destroyed. The deaths from intercurrent infection are not accurately known except in those laboratories where careful records are keptand there are too many where they are not. A. A. Tuffery, speaking at the symposium on epidemiology and laboratory mice, and Dr. J. S. Paterson, in his paper on the control of infection in rabbits, both indicated that such losses are far from negligible, and may on occasion be disastrous; nor can a remedy be proposed in the absence of more detailed recording of incidental losses and their analysis and investigation. This point is to-day widely, if not universally, appreciated, and to recognize a problem is the first stage towards its solution.

The problom is not an exclusively veterinary one. The emphasis in every paper was not so much on the treatment of infection as an untoward experience of individual animals, but on its provention, control and elimination. Prof. W. L. Weipers, in his paper on the control of infection in laboratory cats and dogs, particularly stressed this approach, as did Dr. R. F. Gordon, speaking on the control of infection in laboratory poultry. A more particular approach was indicated by Dr. M. H. Salaman, who has examined vaccination as a method for the control of ectromelia in mouse colonies; and by Dr. Joan Taylor, who dealt with the commonest, and therefore the most important, of all infections-Salmonella infection in laboratory animals. Dr. B. Moore and Dr. A. P. Goffe spoke respectively on infection in laboratory guinea pigs and infections in laboratory monkeys. Indeed, four out of eight titles included the word 'control', and all had a decidedly epidemiological twist. The same theme was emphasized by the chairman, Prof. J. W. Howie, who also added that non-bacteriologists might perhaps with advantage learn to attribute some of their losses, if recorded, to infection rather than to the natural tendency of animals to die.

That laboratory animals do die when they are required to stay alive is beyond dispute. The proportion of those born that fail to survive to weaning age may in some species, for example, rats and rabbits, be as much as one-fifth, or more. Nor are serious losses confined to the nursing period; disease may take its toll on occasion at any age. That the wastage should be so high in rats is alarming; yet very little was mentioned at the meeting about infection in rats, for the reason that very little appears to be known. Something is known about rabbit diseases, but not enough to prevent serious infantile losses. Mouse colonies have been the subject of many classical epidemiological experiments, and some thirty or more incidental infections of mice have been described, four of which are of outstanding importance (ectromelia or mouse pox, salmonellosis, focal necrosis of the liver or Tyzzer's disease, and infantile diarrhœa). Yet, of two out of these four the rtiology is unknown or uncertain, in one the infection is extremely widespread if not universal, and in one only is there any prospect of real control through vaccination.

The situation with regard to guinea pigs is better, for their bacterial diseases at least have been studied in some detail; but new light has been thrown on their possible mode of transmission through the conjunctiva or, possibly, the upper respiratory tract. Nutrition and other environmental factors probably play an important part in the diseases of monkeys, which in any event are too numerous and serious for any degree of complacency. The problem of keeping a considerable number of cats in one place without the serious risk of devastating outbreaks of disease is still unsolved, although much is known about the commoner diseases of this species. Dogs present fewer such problems, perhaps because of the great competence of the veterinary profession with respect to them.

A decade ago, certainly two decades, meetings of this kind might have passed unattended and unnoticed. To-day, the Laboratory Animals Bureau does not lack encouragement to continue to make both the symposium and the congress annual events.

The attendance at the congresses numbers regularly nearly two hundred, and the high standard of con. tributions by technicians is maintained year after year. Of particular interest this year was the paper by Dr. J. F. D. Frazer on some aspects of the breeding of laboratory animals, in which he pointed out the effect on the natural functions of the animal, especially on breeding, of such environmental factors as light, heat, diet, cage-size and design, quality of care and much besides. He was addressing technicians, animal technicians for the most part, and he seemed to be inviting them to make their own contributions to knowledge of animal care and good husbandry.

This brings up a point of more than trivial interest. The term 'animal technician' first achieved formal status six years ago, when the Animal Technicians Association was founded. After six years it is time for it to be generally adopted and for the older terms applied to animal house staff to be dropped. The 
grade of animal technician is recognized by many employing authorities, such as the Medical Research Council, which have undoubtedly learned that good animal technicians mean good animal material for research and investigation. Some universities recognize the grade, but others do not; the National Health Service does not, nor is the animal technician represented on the Whitley Council. Where recognition has occurred, it has been found to pay in terms of better animals, better work and (if costa are known) less extravagance through avoidable wastage. Why, then, are some employing bodies reluctant to follow the excellent lead given by others? No animal houses in Great Britain are so bad that they could not be worse; but many are not so good that they could not be better if unskilled labour were to be gradually replaced by qualified animal technicians.
Although we may regard our standards in Britain with some satisfaction (but with no complacency), too many laboratory animals still die of infection. Some of this wastage could be prevented by more skill employed in their care and management, by the application of existing knowledge of laboratory animal diseases, and by the investigation (mainly epidemiological) of diseases still imperfectly understood.

The symposium will be fully reported in Laboratory Animals Bureau Collected Papers, Vol. 4 (obtainable from the Bureau at the Medical Research Council Laboratories, Holly Hill, London, N.W.3). The Congress will be fully reported in the Journal of the Animal Technicians Association (obtainable from the honorary secretary of the Association, Mr. A. E. Mundy, 5 Ouse Bridge Drive, Carlton, Notts).

W. LANe-Petter

\section{FOOD TECHNOLOGY AND NUTRITION}

T HE 101st meeting of the Nutrition Society (the 46th meeting of the Scottish Group) was held in the Biochemistry Department of the University of Edinburgh on April 28, under the chairmanship of Prof. G. F'. Marrian, when the subject of "The Impact of Food Technology on the Nutrition of Man and Animals" was considered. In opening the meeting, Prof. Marrian stressed the enormous importance of the topic under discussion, since so much food is processed. As one speaker pointed out, if it is accepted that food processing includes all treatment received by a foodstuff from its point of origin to the point in space and time when it is consumed, then barely 2 per cent of our food expressed in terms of calories receives no processing. Prof. Marrian also referred to the bigger and almost frightening problem of world food production, and suggested that the topics to be discussed that day warranted consideration over at least several days.

The first paper, on food processing and nutritional values for man, was by Dr. H. R. Barnell and Miss D. F. Hollingsworth, of the Ministry of Agriculture, Fisheries and Food. Miss Hollingsworth, who read the paper, pointed out that the application of heat to starch is essential for its digestion; that excessive heating of fat may cause production of acrolein ; and that proteins are sensitive to the application of excessive heat and to the removal of heat. Starch, sugars and proteins in foods are not normally affected by atmospheric oxygen; but powerful oxidizing agents may have an effect. Fats may become rancid on storage, particularly in the presence of air. Rancidity may also be caused by the activity of micro-organisms. Development of oxidative rancidity is affected by temperature, light, moisture and by traces of various minerals (cobalt, copper, iron and manganese) and can be controlled by addition of antioxidants. Rancidity, besides reducing the value of fat, has adverse nutritional side-effects. Of the fat-soluble vitamins, vitamin $\mathbf{A}$ is relatively stable to heat if oxygen is excluded. Light also accelerates oxidation. Vitamin $\mathrm{D}$ is moderately stable to heat, light and oxygen. Vitamin $\mathrm{E}$ is fairly stable to heat but is destroyed during development of oxidative rancidity in fats. Riboflavin and nicotinic acid are more stable to heat than vitamin $B_{1}$, which is the most labile of the $B$ complex. Riboflavin is unstable to heat and light. Vitamin $\mathrm{C}$ is unstable in presence of oxygen and is destroyed in sunlight.

It is possible that a combination of light, heat treatment and a radiation sterilization treatment will give eventually more attractive products than those produced by present methods. While on the whole it is true that the effects of processing on the nutrients in foods tend to give an impression of losses of nutrients whenever a food is given any form of treatment, it was emphasized by Miss Hollingsworth that the processing of foods is to a large extent a necessity to make them edible and palatable, transportable and storable. The final result is therefore greatly to increase the supply of nutrients to the world's populations.

Dr. J. M. Barnes, of the Medical Research Council's Toxicology Unit, followed next with a paper on the potential toxicity of chemicals used in food technology. He mentioned that many of the substances used as food additives possess no outstanding toxic property; others which may be used as adjuncts in processing or preservation may be toxic, but are present in the food only in very small quantities. The study of non-toxic substances resolves itself into the problem of trying to prove a negative.

Food manufacturers and allied commercial interests are so aware of the problem of toxicity that Dr. Barnes considered it unlikely that any material with demonstrable toxic properties will ever be included in food prepared in accordance with reputable trade practices. However, these may appear in food in trace quantities as the result of current practices such as compounds with well-marked toxic properties and active as insecticides, fungicides, germicides or endowed with other special properties. A safe dose is one which the body can dispose of without harm to its normal metabolism. Difficulties arise when no clearcut toxic response occurs with larger doses. There are some who suggest that in some unspecified way the prolonged consumption of such substances over long periods may injure health. It has been shown that, in the case of certain toxic substances, the disposal of small non-toxic doses may be quite different from that used when larger quantities are given. 